\title{
DIREITO TRIBUTÁRIO INTERNACIONAL - ELEMENTOS DE CONEXÃO NO COMÉRCIO EXTERIOR DE SERVIÇOS E INTANGÍVEIS
}

\author{
INTERNATIONAL TAX LAW - CONNECTING FACTORS TO INTERNATIONAL TRADE OF SERVICES
}

AND INTANGIBLES

Ana Clarissa Masuko*

Resumo:

O artigo visa a traçar um breve panorama das técnicas de tributação do comércio exterior de serviços e intangíveis. O tema se insere no contexto da economia digital, que traz situações inéditas para a realidade social. Para o Direito Tributário Internacional traz ingentes desafios, a começar pela questão de rastreabilidade dos fatos geradores e a heterogeneidade dos bens intangíveis.

Palavras-chave: Direito Tributário Internacional. Elementos de conexão. Princípio do destino. Comércio. Serviços Intangíveis.

\begin{abstract}
:
The paper aims to outline a brief overview of taxation techniques for foreign trade in services and intangibles. The subject is inserted in the context of the digital economy, which brings unprecedented situations to social reality. For International Tax Law, there are many challenges, starting with the question of traceability of the triggering event of the tax obligations and the heterogeneity of intangible assets.
\end{abstract}

Keywords: International Tax Law. Connecting factors. Principle of destination. Trade. Services. Intangibles.

\section{Introdução}

Os elementos de conexão operam como "pontes" entre ordenamentos jurídicos, por estabelecerem a ligação entre pessoas, objetos e fatos descritos nas hipóteses de incidência normativa, com determinado ordenamento jurídico (XAVIER, 2009, p. 223).

Os enunciados jurídicos de conexão compõem norma jurídica de estrutura, originada da combinação de norma jurídica interna e de tratados internacionais, que determina o exercício de jurisdição tributária, no contexto de conflito de ordenamentos jurídicos.

A determinação dos elementos de conexão terá como fundamento o princípio da territorialidade, na medida em que um Estado será legitimado para exercer a sua soberania tributária quando houver um vínculo com seu território. Esse vínculo

\footnotetext{
* $\quad$ Doutora em Direito Tributário pela Universidade de São Paulo; Mestre em Direito Tributário pela Pontifícia Universidade Católica de São Paulo; Bacharel em Direito pela Universidade de São Paulo.
} 
poderá ser de natureza subjetiva (como nacionalidade ou residência) ou objetivo (como o local de produção ou consumo).

Para se estruturar legitimamente as normas de conexão, seus critérios devem ser fundados em laços que evidenciem o liame econômico-político entre o evento tributável e uma jurisdição, sob o princípio da territorialidade, além da observância dos princípios que edificam o ordenamento jurídico e o costume internacional.

Sob a perspectiva interna de um ordenamento jurídico, a Constituição informará quais são os pilares de determinado sistema tributário, os vetores teleológicos que o saturam, os parâmetros ou a estrutura da tributação indireta, a forma como o ordenamento jurídico interno relaciona-se com as normas de Direito Internacional.

Adicionalmente, um Estado deverá tomar em consideração não só as possibilidades para legislar sobre o tema, de criar normas gerais e abstratas, como também, as possibilidades efetivas de coagir um contribuinte ao cumprimento da prescrição normativa. ${ }^{1}$

Nos tributos indiretos incidentes sobre o comércio exterior, em que se tem, subjacente, uma operação de compra e venda de mercadorias ou de serviços, os critérios de conexão empregados são o do país de origem da produção ou fornecimento dos bens e o país de destino, em que a tributação se aloca onde os bens são consumidos.

A adoção do princípio do destino implica na desoneração da carga tributária nas saídas voltadas à exportação e a restituição ou creditamento da carga tributária que incidiu na cadeia de produção e distribuição do bem, internamente, bem como a não discriminação no tratamento tributário atribuído à mercadoria estrangeira, em relação à nacional.

$\mathrm{O}$ princípio do destino coaduna-se à racionalidade própria dos tributos indiretos, que têm como escopo captar a capacidade contributiva do consumidor, de sorte que a receita tributária é revertida para o Estado onde há o consumo dos bens.

No comércio exterior de serviços não se estruturará a tributação sobre o regime jurídico aduaneiro, pelo simples fato de que não ingressam ou saem do território pelas fronteiras do país. Os controles aduaneiros são ineficazes para bens incorpóreos, como serviços, produtos digitais e outros intangíveis, o que demanda outras técnicas de tributação, num contexto denominado por estudiosos de "borderless economy", ou economia sem fronteiras (HELLERSTEIN, 2009, p. 554).

Todavia, se no comércio exterior de mercadorias há certa uniformidade nos ordenamentos jurídicos, para o estabelecimento dos elementos de conexão, no caso dos serviços, flagram-se muitas divergências.

A territorialidade formal ou "jurisdicition to prescribe", abordada no capítulo 2. 
Há diversos tipos de elementos de conexão que podem ser eleitos para edificar a tributação do comércio exterior de serviços. O local em que a fatura comercial é emitida ou parte do pagamento é realizado, faz presumir que houve o fornecimento do serviço. Da mesma forma, o local do imóvel onde o serviço é prestado, a residência do consumidor, são elementos de conexão legítimos para indicar o local de consumo.

A eleição de elementos de conexão poderá estar correlacionada com a natureza do serviço prestado - um determinado ordenamento jurídico poderá erigir seu direito positivo elegendo diversas presunções em referência aos diversos tipos de serviços, bem como, dentre elas, estabelecer hierarquia de aplicação e combinação.

A seguir, discorre-se sobre alguns critérios para a estruturação das normas de tributação no comércio exterior de serviços e aplicação do princípio do destino.

2. Definições e formas de fornecimento de serviços

Uma das grandes dificuldades, senão a maior, na tributação dos serviços é a própria qualificação de "serviços", muito diversificada nos ordenamentos jurídicos ao redor do mundo.

Com efeito, o motivo pelo qual não foi veiculada uma definição de serviços no General Agreement on Trade in Services (GATS), da Organização Mundial do Comércio, foi a falta de consenso durante as negociações, o que redundou no fato de que, embora o acordo gere diversas obrigações, os membros podem impor restrições em seus compromissos específicos, por meio de listas positivas (MATSUSHITA, 2003). ${ }^{2}$

Essa controvérsia impactará na operacionalização do princípio do destino, pois a falta de limites precisos para a definição de serviços impacta diretamente na grande quantidade de elementos de conexão possíveis para a estruturação da tributação.

A Organização para Cooperação e Desenvolvimento Econômico (OCDE), em suas orientações para tributos sobre valor agregado, ${ }^{3}$ estabeleceu categorias de serviços entre tangíveis e intangíveis.

Os serviços tangíveis seriam aqueles que teriam um liame suficiente com bens corpóreos móveis ou imóveis, a justificar que seu consumo se realize no mesmo local destes, como arquitetura, acomodação de hotel, transporte e os serviços logísticos correlatos. ${ }^{4}$ Se o serviço demandar a presença física do prestador, como eventos esportivos, concertos, cabeleireiros, restaurante, será classificado como serviço tangível.

\footnotetext{
2 As listas positivas determinam quais os compromissos os Estados acordam em submeter às regras do acordo, ao passo que nas negativas, listam os serviços excluídos do acordo.

3 Disponível em: < http://www.oecd.org/tax/consumption/Taxation\%20and\%20eCommerce\%202001.pdf>.

$4 \quad$ No original:

Services may be broadly categorised as either those that are tangible, where the place of consumption can
} 
Os serviços intangíveis, por sua vez, não possuem essa conexão com o mundo fenomênico, demandando presunções específicas para a determinação da jurisdição competente, como a da localização do consumidor ou recebedor dos bens, local de seu estabelecimento, domicílio ou residência. Exemplos de serviços intangíveis seriam os de contabilidade, consultoria e serviços intelectuais, em geral, financeiros, de publicidade, de transferência de direitos de propriedade, provisão de informações, telecomunicações, de transmissão, ou qualquer outro serviço apto a ser entregue por meios eletrônicos.

De forma análoga, como já referido, na União Europeia é esse o critério adotado, pois o Imposto sobre Valor Agregado (IVA) grava tanto mercadorias como serviços, tratando os últimos como categoria residual, dos bens não corpóreos - tudo o que não for corpóreo, será considerado serviço, como livros digitais, filmes, jogos.

Os serviços tangíveis, em princípio, compatibilizar-se-iam com elementos de conexão objetivos, vinculados ao território. Os serviços intangíveis, por sua vez, ofertariam maiores dificuldades, pois, muitas vezes, os elementos de conexão passíveis de serem empregados, seriam subjetivos.

De se notar que a depender da configuração das competências na tributação indireta assumida por determinado Estado, o critério classificatório que toma em conta a tangibilidade e a intangibilidade, de fácil operacionalidade, será insuficiente ou desprovido de utilidade, para efeitos de fixação de competência tributária.

É o caso do sistema tributário brasileiro, no qual a tributação indireta é dividida entre os três entes federativos, sendo relevante observar que a competência para a tributação geral sobre os serviços é municipal, mas circunscrita a uma lista taxativa, a União detendo competência geral, tanto para bens corpóreos como incorpóreos, e os Estados, sendo competentes para serviços específicos e para tributação dos bens corpóreos. Tal arquétipo de competências determina que se erijam diversos critérios para a tributação dos serviços.

Marco Aurélio Greco observa que, sob a égide do sistema constitucional brasileiro, não seria possível uma definição de "serviços" pela negativa, em virtude das competências constitucionais autônomas dos Estados e dos Municípios, sobre serviços. Apenas seria cabível uma definição positiva, pois "serviço precisa ser alguma coisa" (GRECO, 2003, p. 879).

Não se pode deixar de atribuir especial ênfase na revolução ocasionada pelos avanços tecnológicos na telecomunicação. A noção tradicional segundo a qual, o

be readily identified, or those that are intangible, where the place of consumption may be uncertain. While this categorisation is not a technical one, it helps to illustrate how, in relation to certain transactions, difficulties in determining the place of consumption can arise. (OECD, 2001, p. 24-25). Disponível em: $<$ http://www.oecd.org/tax/consumption/Taxation\%20and\%20eCommerce\%202001.pdf>. 
consumo de serviços ocorrerá no local onde reside o prestador passa a não corresponder à realidade, no ambiente da economia digital (SEVILLA SEGURA, 2004, p. 473). ${ }^{5}$

Com essa nova realidade, aflora a problemática do controle e administração tributária, a um problema conceitual, pois com as possibilidades criadas com os avanços tecnológicos, é comum que não se possa precisar a localização do tomador ou do prestador vendedor e, por conseguinte, a jurisdição fiscal competente.

Nas transações com bens incorpóreos, não há movimento físico, de forma que a fiscalização deverá encontrar instrumental técnico diferenciado para apreender esses eventos tributáveis.

Nas situações em que o adquirente de bem incorpóreo é o consumidor final, a dificuldade de implementação da tributação é ainda maior, de maneira que a solução para a evasão fiscal apenas pode se dar em um contexto de alta cooperação internacional ou de alternativas como estabelecimento de declarações do consumidor, responsabilização das empresas de cartão de crédito, já que são estes meios geralmente aceitos para os pagamentos.

Com relação às operações entre pessoas jurídicas (“B2B”), mais fácil se faz o controle das operações - no caso do IVA, o "efeito recuperação" leva ao pagamento do imposto no momento da venda do bem, a contabilidade das aquisições, os contratos, enfim, há maior documentação das operações.

\section{Contrato de prestação de serviços}

De acordo com a premissa de que os tributos indiretos pressupõem transações, tendo como escopo negócios jurídicos de fornecimentos de bens corpóreos e incorpóreos, na sua estrutura normativa, terá hipótese as relações jurídicas contratuais enlaçadas, pelo nexo de causalidade jurídica, as relações jurídicas reciprocamente vinculadas, em que há duas obrigações, atreladas a duas prestações, em relações conversas, sinalagmáticas.

A norma jurídica de conexão terá, por sua vez, em sua hipótese de incidência, o evento da ocorrência da celebração do contrato de prestação de serviços, com elemento internacional ou de estraneidade.

\footnotetext{
$5 \quad$ Nas palavras de José V. Sevilla Segura:

Como antes vimos el viejo criterio de asociar el lugar donde se produce el consumo con el lugar donde se encuentra el comerciante minorista no es siempre aplicable y mucho menos, desde luego, tratándose de comercio electrónico donde, en el caso que podamos saber dónde se encuentra el vendedor, pudiera ocurrir que estuviera a miles de kilómetros y, desde luego, en una jurisdicción muy lejana de aquella en la que se produce el consumo. Y otro tanto puede decirse de las transacciones en las que el adquiriente es un empresario. En consecuencia, esta realidad, como ya advertíamos, nos obligue a situar la atención en el adquiriente y en su lugar de residencia habitual y será aquí donde deba establecerse el gravamen y la hacienda correspondiente a esta jurisdicción la que deba recaudar el tributo.
} 
A norma jurídica promove um corte metodológico, elegendo apenas um dos aspectos do referido negócio jurídico - o elemento de conexão - para, no seu consequente, veicular a relação jurídica em que determinado Estado surge como competente para tributar aquela operação, isto é, a jurisdição fiscal competente:

A jurisdição competente não é apenas resultado de aplicação simples do enunciado prescritivo que veicule um elemento de conexão, como, por exemplo, o local da residência do tomador, porém, o resultado da interpretação sistemática de diversos enunciados atinentes a critérios de conexão, de determinado ordenamento jurídico. A norma jurídica de conexão é norma de estrutura que determinará qual a jurisdição fiscal competente, nas hipóteses de fornecimento de serviços, com elemento internacional.

A norma jurídica de tributação ou a regra-matriz de incidência será o resultado da combinação lógica de ambas as normas, a do negócio jurídico propriamente dito, do qual, advirá relações obrigacionais que, por deterem elemento internacional eleito como elemento de conexão no âmbito de determinado ordenamento jurídico, atribuirá a competência para tributar a determinada jurisdição fiscal.

O legislador poderá, validamente, eleger qualquer um dos aspectos que gravitam em torno da relação contratual, indiciários do fato "consumo".

Os modelos que se apresentam para determinação do local do consumo são bastante variados. Não obstante, as possibilidades para determinação dos elementos de conexão estão circunscritas ao contrato de serviços, que refletirá como se dá o fornecimento, servindo de importante referência para as partes e para as administrações tributárias, especialmente para identificar o consumidor.

E "contrato" deve ser entendido em sua acepção mais ampla, de negócio jurídico, não limitado a instrumento contratual formal, que muitas vezes inexiste, em prol da agilidade e dinâmica das transações. A troca de correspondências, e-mails, faturas, ordens de pagamentos, recibos, bem como quaisquer documentos que demonstrem a transação subjacente. Nessa acepção ampla possibilita-se a inclusão de serviços fornecidos entre fornecedores ou a consumidor final.

Luís Eduardo Schoueri, vislumbrando a natureza transacional do fato gerador do Imposto Sobre Serviços de Qualquer Natureza - ISSQN, afirma que o termo "resultado" sempre deverá ser lido à luz do contrato de prestação de serviços, verificando a partir da causa ou objeto contratual e quais são seus limites (SCHOUERI, 2004). ${ }^{6}$

Em suas palavras:

A idéia de causa da contraprestação é fundamental para que se encontre o resultado. Afinal, se um contrato de prestação de serviços é sinalagmático, deve-se compreender que do tomador de serviço é exigido o pagamento do seu preço em virtude de uma utilidade que lhe é prometida. Assim, importa, para cada contrato de prestação de serviços, examinar, a partir de seu objeto, a causa do contrato. Não é, pois, qualquer vantagem que será suficiente para se considerar o resultado do serviço alcançado no território 
O instrumento contratual assume importância fundamental nos serviços, pois, diferentemente da compra e venda de bens corpóreos, a intangibilidade dificulta a delimitação, no mundo fenomênico, dos efeitos do negócio jurídico. A análise do objeto contratual trará subsídios para que se possam verificar questões essenciais, como a identidade das partes, do beneficiário efetivo, o serviço contratado e, assim, depreenderse o local do consumo dos bens, permitindo o corte que delimite o objeto do serviço.

O que extrapolar os contornos desse objeto contratual, não serão relevantes para determinação de jurisdição fiscal competente. Caso fossem considerados todos os efeitos decorrentes do fornecimento de um serviço, a norma teria um raio de incidência tão amplo, que impossibilitaria a estruturação normativa da tributação do comércio exterior de serviços.

Nesse contexto, Gabriel Lacerda Troianelli e Juliana Gueiros dão, como exemplo, o caso de um investidor residente nos Estados Unidos, que contrata uma empresa brasileira para realizar análise econômico-financeira da economia brasileira. A conclusão do estudo poderá levar o investimento ao Brasil ou para outro mercado; seja qual for o desfecho, investimento no Brasil ou na China, o resultado do serviço considera-se ocorrido nos Estados Unidos e a operação, de exportação de serviços. A cadeia de eventos posteriores seria mediata, indireta, sendo irrelevante para a tributação (TROIANELLI; GUEIROS, 2004, p. 202). ${ }^{7}$

Não se perdendo de vista, frise-se, que essas questões deverão ser sistematicamente interpretadas com as disposições de determinado ordenamento jurídico, que trará o recorte específico do evento, relevante para a tributação. O operador do direito, seja o contribuinte na determinação de sua obrigação tributária, seja a administração tributária, deverá verificar os serviços contratados, para delimitar precisamente qual o seu objeto, causa, partes, estabelecendo o corte necessário para a aplicação da norma.

4. Elementos de conexão subjetivos

No comércio exterior de serviços a sujeição passiva recairá sobre o tomador, na medida em que está diretamente vinculado ao fato jurídico "consumo" ou sobre o

nacional. Importará investigar aquela vantagem ou proveito que foi o próprio objeto: o que o serviço deveria proporcionar a seu tomador.

7 Nesse sentido, afirmam os autores:

Dessa análise conclui-se que dois elementos são vitais para a caracterização do 'resultado' (e o respectivo local de ocorrência): (i) o beneficiário efetivo do serviço (quem está consumindo) - que deve estar fixado no exterior para que haja exportação -, e (ii) a delimitação dos efeitos imediatos diretos da prestação de serviço, descartando-se de plano quaisquer efeitos secundários. 
contribuinte de direito, quando se torna o responsável outra pessoa da cadeia, não sendo ele próprio, consumidor final.

Alguns ordenamentos jurídicos, como o da União Europeia, adotam elementos de conexão subjetivos, como regra geral para a tributação de serviços, atrelando a jurisdição fiscal competente à localização dos sujeitos da relação obrigacional.

Os elementos de conexão subjetivos são considerados apropriados para formas de prestação de serviço nos quais não se demanda a presença física de tomador e prestador, podendo ser prestados remotamente (offshorable), e o consumo não se dá concomitantemente à prestação do serviço. Dentre esses serviços, podem ser citados os serviços de consultoria, de contabilidade, de assistência técnica, de fornecimento de softwares digitalmente, serviços financeiros e de seguro.

Tradicionalmente, a tributação era fundada em elementos objetivos ou reais. A evolução histórica e a globalização acarretaram, nos dizeres de José Casalta Nabais, a "crescente desmaterialização dos pressupostos de facto dos impostos e a tendência de personalização da tributação" e em decorrência, a preferência por elementos de conexão subjetivos, como o estabelecimento, domicílio e residência dos contribuintes (NABAIS, 2005, p. 205).

Vários elementos de conexão subjetivos podem ser escolhidos pelo legislador, como a localização (MILLAR, 2004, p. 288):

- da residência ou estabelecimento (place of business) do fornecedor;

- da residência ou estabelecimento do recebedor do fornecimento;

- de residência, ou estabelecimento do consumidor (se aquele que recebe e o que consome o serviço são entidades diversas);

- o local do efetivo uso (effective use or enjoyment);

Nas hipóteses de fornecimento a consumidor final ("B2C", business to consumer), a OCDE fixa a residência ou domicílio do tomador de serviços como o elemento de conexão. Nas hipóteses de fornecimentos de serviços entre pessoas jurídicas ("B2B", business to business), o local do estabelecimento do destinatário dos serviços.

4.1. Prestação de serviços entre pessoas jurídicas ou "B2B"

Nas operações B2B, a norma de conexão deverá ser estruturada de tal forma que enfoque o local onde se encontra o tomador do serviço, enquanto um dos elos da cadeia de fornecimento, sem perder de vista, a forma de facilitar a transferência do encargo financeiro para o consumidor final. 
A aquisição do serviço no âmbito da cadeia de fornecimento poderá ser contínua, esgotar-se em uma única utilização, ser tomada como insumo, suportar a atividade do adquirente no geral, hipóteses que dificultam a delimitação do regime jurídico do serviço.

Nesses casos, os fornecedores poderão fazer registros específicos nas jurisdições fiscais de consumo, com número de identificação e outros procedimentos de controle e deverá haver a previsão no direito positivo aplicável ao tomador, de creditamento do imposto pago para que repasse o encargo, caso o próximo elo da cadeia não seja o consumidor final. ${ }^{8}$

$\mathrm{Na}$ determinação das normas de conexão para as operações B2B, o contrato será fundamental para a identificação do tomador do serviço, em sua acepção mais alta, enquanto acordo que permita identificar o enlace obrigacional entre o prestador e tomador de um serviço, em torno de um objeto e que possa ser (re)constituído juridicamente por meio de diversas provas, como e-mails, faturas, gravações, outros instrumentos contratuais, a depender de cada ordenamento jurídico.

Caso o serviço seja tomado por um grupo econômico, o elemento de conexão subjetivo poderá ser o local em que estiver a pessoa que efetivamente usou o serviço, o que poderá levar a desdobramentos, que tornam a operação mais complexa.

Nos grupos econômicos, muitas vezes, um determinado serviço poderá ser contratado para ser utilizado por diversas empresas, como casos de serviços administrativos e técnicos, e da mesma forma, poderá ser adquirido um serviço, que, de antemão, não se saiba predizer aonde será utilizado.

Em face das dificuldades para a determinação da jurisdição fiscal competente, poderá ser eleito um elemento de conexão que se refira ao local de entrega do serviço (GREGGI, 2010, p. 708), ${ }^{9}$ ou se utilizar do próprio contrato de rateio (cost sharing agreement) entre as empresas do grupo, para proporcionalizar a tributação de acordo com os custos incorridos por cada uma.

Nem sempre o tomador do serviço, que figura contratualmente como tal e que muitas vezes realiza o pagamento, é o beneficiário da prestação, isto é, aquele que efetivamente consumiu o serviço.

Em muitos ordenamentos jurídicos, determina-se a sujeição passiva atribuída ao beneficiário efetivo, no intuito de erigir uma norma antielisiva específica (MACEDO, 2011, p. 22) ou para implementação de regra de conexão do consumo efetivo (use or enjoyment rule), visando-se a evitar situações tais como as de grupos econômicos,

(OECD, 2015a, p. 28). Disponível em: <http://www.oecd.org/ctp/consumption/international-vat-gstguidelines.pdf $>$.

$9 \quad$ Esse é o caso do IVA europeu. 
com atuação em diversas jurisdições fiscais, que engendram estruturas para a redução da carga tributária.

O conceito de beneficiário efetivo (beneficial ownership) é bastante estudado na esfera das convenções internacionais para se evitar a bitributação da renda, com relação aos artigos sobre dividendos, juros e royalties, como medida para impedir o uso das convenções em operações de evasão, elisão fiscal internacional, por meio de treaty shopping (TERSI, 2014, p. 4). A tendência deverá ser a evolução do seu estudo na tributação indireta dos serviços, pois a mobilidade das formas dos fornecimentos, oportunizam o uso de planejamentos tributários.

Outro aspecto relevante para a fixação das competências tributárias, é a delimitação do alcance de "estabelecimento permanente", objeto de candentes debates na seara da tributação direta.

Na União Europeia, a definição de estabelecimento permanente no âmbito do IVA, está sendo construída pela Corte de Justiça Europeia, que chegou a um conceito, no caso Berkholz, ${ }^{10}$ no qual, na determinação do local do consumo de um serviço, com base em um conceito de "estabelecimento" de um contribuinte, deveriam ser verificados alguns critérios como tamanho mínimo, a existência de recursos humanos e técnicos suficientes para a prestação do serviço, a presença permanente e independência (RENDAHL, 2009, p. 10).

O regulamento de execução, ${ }^{11}$ que disciplina a Diretiva 2006/112/CE, no art. 11, traz o conceito de "estabelecimento estável” como

caracterizado por um grau suficiente de permanência e uma estrutura adequada, em termos de recursos humanos e técnicos, que lhe permitam receber e utilizar os serviços que são prestados para as necessidades próprias desse estabelecimento.

O recente GST australiano vale-se do conceito de estabelecimento permanente trazido do Income Tax Assessment Act de 1936, que determina que o estabelecimento permanente se caracteriza quando uma pessoa conduz um negócio por intermédio de um agente, usa ou instala equipamentos ou maquinários substanciais, desenvolve um projeto de construção, ou desenvolve negócios de venda de bens, realiza manufaturas, ensamblagens, processamentos, empacotamento de produtos (MILLAR, 2004, p. 37).

\footnotetext{
10 Disponível em: < http://eur-lex.europa.eu/legal-content/EN/TXT/?uri=CELEX\%3A61984CJ0168>.

11 Disponível em: <http://eur-lex.europa.eu/legalcontent/PT/TXT/PDF/?uri=CELEX:32011R0282\&qid=145 8995613456\&from $=\mathrm{EN}>$.
} 
A crítica para essa configuração de estabelecimento permanente é que os requisitos exigidos, historicamente defendidos pela OCDE, com o desenvolvimento dos meios de locomoção e as conquistas no campo das telecomunicações evidenciam a crescente prescindibilidade de um estabelecimento permanente para a realização de

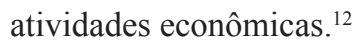

Tanto mais evidente é o esvaziamento econômico do conceito de "estabelecimento permanente", nas hipóteses do comércio eletrônico, a despeito da reiteração da OCDE quanto à sua persistência. A territorialidade estrita perde importância, pois podem ser vendidos bens por todo o mundo, sem a necessidade de presença física, não sendo mais necessária a presença material para se operar em determinada economia.

Por essa razão, estuda-se a revisitação do conceito de "estabelecimento permanente" pelo prisma dos avanços da informática e do comércio eletrônico, em vista dos conflitos que exsurgem entre países provedores de tecnologia (exportadores), que usualmente tributam a renda com base no princípio da residência, e compradores (importadores), que tendem a tributar as operações, com base no princípio da fonte, além da tendência das empresas exportadoras de tecnologia, tenderem a se instalar em países com tributação privilegiada (ADONNINO, 2003, p. 503).

Contudo, ainda prepondera a imposição da tributação, levando em conta a necessidade de um estabelecimento permanente e a constatação que este inexistirá em muitas transações, acaba por atrair a competência tributária para o país de residência, favorecendo os países exportadores de capital. ${ }^{13}$

\subsection{Serviço para consumidores finais ou "B2C"}

A forma tradicional de fornecimento de serviços é diretamente a consumidores finais. O arquétipo de um típico fornecimento de serviços pressupunha que tanto prestador como tomador estivessem na mesma jurisdição fiscal. Ainda que uma das partes da relação fosse vinculada a outra jurisdição fiscal, essa circunstância tinha pouca relevância para a determinação da competência tributária, pois o serviço era consumido no território do fornecedor, de sorte que era possível tomar como elemento de conexão, a localização do prestador (MILLAR, 2008, p. 175-214). ${ }^{14}$

12 Nesse sentido, da mesma forma, Marco Aurélio Greco, que afirma que a internet e o desenvolvimento tecnológico, desafiam os conceitos do Direito Tributário, como o de "estabelecimento permanente". Seria considerado um lap top um estabelecimento permanente, se um engenheiro o utiliza na montagem de uma máquina, pois através dele efetua testes, verificações, conectando-se com a matriz? (GRECO, 2000, p. 56).

13 Nesse contexto, a crítica de Marco Greggi, para quem a tributação dos serviços pelo IVA europeu parece se inspirar em regras mais pertinentes aos tributos diretos, enfatizando o domicílio e a residência, ao passo que os tributos indiretos, devem perseguir o local em que os serviços foram efetivamente consumidos.

14 Nesse sentido, Rebecca discorre sobre as normas de União Europeia, que se valiam de uma "proxy" para 
Os fornecimentos digitais descortinaram uma nova realidade, na qual a presença física para o fornecimento de serviço é prescindível, de maneira que um elemento de conexão baseado na localização do prestador afasta-se do evento que se visa a tributar, o consumo. Da mesma forma, não restará claro o local da prestação dos serviços, pois a sua natureza incorpórea permitirá que possa ser executado remotamente pelo prestador, como uma assistência técnica de informática por meio de computador localizado em jurisdição distinta da do tomador.

Portanto, alguns ordenamentos jurídicos passaram a adotar elementos de conexão subjetivos para as transações B2C, tornando o local de domicílio do consumidor final como o elemento de conexão principal para a tributação, considerando que é razoável presumir que o consumo do bem, nessas hipóteses, dar-se-á nessa jurisdição.

Nesses casos, o contrato de prestação de serviços terá menos importância, pois a característica das transações, especialmente no comércio eletrônico, envolve grande volume de transações, de baixos valores, sem que haja muita interação entre o fornecedor e o tomador.

As informações que determinarão a competência tributária poderão ser munidas pelo fornecedor, que deterá os dados do tomador, obtidos nos cadastros de pedido, pelos dados bancários e de cartão de crédito, o protocolo de internet (Internet Protocol address) do equipamento pelo qual se fez o download do bem ou pelo número de telefone.

\section{Elementos de conexão objetivos}

A análise dos ordenamentos jurídicos demonstra que os elementos de conexão objetivos mais comuns são o local do bem imóvel, das mercadorias, da prestação ou performance de um fornecimento, de venda, dos bens em relação aos quais os serviços serão prestados.

uma "proxy", no sentido de que o local do fornecedor era usado como uma presunção de que lá se localizava o consumidor, presumindo-se, portanto, que naquele local, também ocorrera o consumo:

The basic rule is that the place of supply of services is the place where the supplier has its place of business, or has a fixed establishment through which the supply is made, or in the absence of such a place, the person's permanent address or usual residence. While this looks like the origin principle, it should not be assumed that this is the intention. On the contrary, the supplier's residence is used as a proxy for a proxy: if it accurately predicts the location of the consumer, it will operate as a destination principle proxy. The European place of supply rules were drafted at a time when consumers mostly purchased services from local suppliers, which made the supplier's location an effective proxy for the recipient's location, which was itself considered a proxy for the place of consumption. 
Trata-se de hipóteses nas quais o local do consumo é prontamente identificável ou que não podem ser entregues de locais remotos, como serviços de hotelaria, transporte, aluguel de veículos e cabeleireiro.

A OCDE estabelece como parâmetros para a escolha do elemento de conexão, a neutralidade, a eficiência e baixos custos de conformidade na administração do tributo, tanto para contribuintes, quanto para as administrações tributárias; segurança e simplicidade na formulação dos critérios, que possibilitem a fácil compreensão pelos operadores; a efetividade e razoabilidade, para que a evasão e a elisão sejam minimizados, com medidas de contenção proporcionais aos riscos envolvidos. ${ }^{15}$

\subsection{Local da prestação do serviço}

O local da prestação ou execução do serviço, isto é, aquele no qual o serviço desenvolveu-se, poderá ser estabelecido como elemento de conexão nas hipóteses nas quais esse local está associado ao de consumo, demandando a presença física do tomador e/ou do prestador.

Nesses casos, o local de execução do serviço é facilmente identificado, sendo o seu consumo imediato, concomitantemente à sua performance e por essa razão, é um elemento de conexão prático e eficiente

Nos fornecimentos conhecidos como "on the spot supply" ou de fornecimentos locais, demanda-se a presença física do prestador e do tomador, para a realização da transação. Os exemplos dessas modalidades de serviços são os de cabeleireiro, massagem, hotelaria, restaurante, buffet, catering, fisioterapia, museu, performances artísticas, feiras de negócios, teatro, circo e competições esportivas. ${ }^{16}$

Os serviços normalmente oferecidos a um número grande de consumidores, em pequenas quantidades e em curtos períodos, inviabilizam o emprego de elementos de conexão subjetivos, pois se geram custos de conformidade exacerbados aos fornecedores, além de pouca eficiência para as autoridades, no intento de se certificar se efetivamente o consumidor estaria estabelecido em outro país.

Outros tipos de serviço, que demandem a presença física apenas do tomador, poderão predizer, com certa segurança, o local do consumo, como nos casos de utilização de serviços de telefonia em hotel, acesso de internet em cybercafé.

Entretanto, embora o critério pareça não ofertar muitas dificuldades de aplicação, a prática é bem mais complexa (RENDAHL, 2009, p. 180). Considerandose que o IVA europeu possui tratamento específico para fornecimentos digitais, em

Conforme preconizado pela Orientação 3.7 da (OECD, 2015a, p. 55).

16 Cf. (OECD, 2015a, p. 46). 
detrimento aos "tradicionais", poderão surgir dúvidas, no caso de serviços fornecidos online. Por exemplo, nos serviços educacionais, o critério de interpretação que se utiliza para qualificá-los como fornecimentos de serviços digitais ou como, simplesmente, educacionais, é o quantum de intervenção humana haverá no caso concreto - se houver pouca ou nenhuma, incide a primeira regra. ${ }^{17}$ Contudo, se o serviço apenas se valer da internet para fazer entrega de materiais, como um instrumento pedagógico, não se distinguirá de um serviço educativo tradicional.

A Corte Europeia tem diversos precedentes relativos ao alcance desse critério de conexão, veiculada em um dispositivo específico na Diretiva do IVA, nomeadamente referente a "serviços culturais, artísticos, desportivos, cientificos, educativos, recreativos e similares, serviços acessórios ao de transporte, peritagem e trabalhos relativos a bens móveis", ${ }^{18}$ como o caso "Dudda" (ECR I-4595). ${ }^{19}$

\subsection{Local do bem}

Nas circunstâncias nas quais os serviços são atrelados a bens corpóreos, sejam móveis ou imóveis, a localização destes será adequado elemento de conexão.

Com relação à prestação de serviços atrelados a bens imóveis, o elemento de conexão atrelado à localização do bem será prático e eficaz para a estruturação da tributação. Exemplificativamente, serviços que se relacionem com direitos de propriedade, como o leasing, de corretagem, conectados à exploração ou utilização do bem; serviços fisicamente prestados no bem imóvel, como reforma, construção, pintura, limpeza; e outros serviços que mantêm um vínculo estreito com o imóvel, como de arquitetura, paisagismo e decoração.

Nessa linha, a OCDE, pela orientação $3.7,{ }^{20}$ estabelece que a jurisdição competente será aquela em que estiver localizado o imóvel, desde que o serviço conectado ao bem seja o principal ou essencial, considerando a operação como um todo.

\footnotetext{
Cf. (OECD, 2015a, p. 19).

Cf. art. 52, Diretiva 2006/112/CE.
}

19 No caso, o Sr. Dudda, estabelecido na Alemanha, tinha um negócio envolvendo o fornecimento de serviços técnicos acústicos, para concertos e serviços semelhantes. A Corte Europeia entendeu que a tributação deveria se dar no local onde o concerto ocorreu, apenas se os serviços de engenharia acústica fossem fisicamente executados no local, como etapa da cadeia da prestação do serviço artístico.

20 No original: Guideline 3.7 -

For internationally traded business-to-business supplies of services and intangibles directly connected with immovable property, the taxing rights may be allocated to the jurisdiction where the immovable property is located. 
A despeito desse critério ser de fácil intelecção, verifica-se que nem sempre será óbvia a conexão do serviço com o bem imóvel. Veja-se o caso de serviços de consultoria jurídica, cujo objeto seja um bem imóvel.

A União Europeia publicou notas explicativas para aplicação da regra de prestação de serviços sobre bens imóveis (Explanatory notes on EU VAT place of supply rules on services connected with immovable property that enter into force in $2017^{21}$ ), estabelecidas no art. 47 da Diretiva IVA, que traz diversas disposições sobre a sua aplicação, como a interpretação do alcance da diretiva, de "propriedade imóvel", de alguns cenários específicos, como o tratamento de serviços jurídicos conectados aos bens imóveis, serviços em imóveis prestados remotamente, casos de fornecimento de mix de serviços, obrigações contratuais complexas, interações entre os elementos de conexão.

Dispõem as notas que a regra específica de conexão atrelada a um bem imóvel visa a assegurar que a tributação ocorra no lugar onde presumidamente ocorreu o consumo do serviço, não podendo os membros deixar de aplicá-la, sobre o fundamento de disposições contratuais que estabeleçam de forma diversa. ${ }^{22}$

Nos casos de serviços em bens móveis, a regra é semelhante à aplicável ao comércio de bens corpóreos, isto é, a localização do bem será o elemento de conexão adequado. Referentes a essas hipóteses, são comuns os serviços de reparação, manutenção e beneficiamento.

Entretanto, nas circunstâncias em que o próprio bem corpóreo deverá se movimentar para que a prestação de serviço seja realizada, a tributação, via de regra, seguirá as normas relativas à tributação aduaneira, pois esses bens deverão cruzar as fronteiras, submetendo-se aos controles aduaneiros. Assim, podem ser aplicados regimes aduaneiros especiais, como de exportação e admissão temporária, em modalidades específicas para submissão do bem corpóreo a serviços, nos quais os tributos aduaneiros ficam suspensos, sob condição resolutiva, apenas sendo devidos os tributos sobre os valores agregados.

${ }^{21}$ Disponível em: < http://ec.europa.eu/taxation_customs/resources/documents/taxation/vat/how_vat_works/ explanatory_notes_new_en.pdf $>$.

22 Diz a nota, no original:

The purpose of the particular place of supply rule on services connected with immovable property is to ensure taxation at the presumed place of consumption of the service. This objective should be recalled in all situations where the practical implementation of the legislation raises difficulties. Such situations should always be resolved in a way as to ensure that the VAT revenue accrues to the Member State where the service is presumably consumed taking into account that services connected with immovable property are considered to be consumed at the place where the property is located. The parties to such transactions cannot therefore circumvent Article 47 of the VAT Directive by indicating in their contractual arrangements that services provided under the contract should rather be subject to the general place of supply rules. 
Em ambos os casos, móveis ou imóveis, há diversas discussões acerca do momento a partir do qual a conexão do serviço com esses bens passa a ser irrelevante, passando outro elemento de conexão, a ser mais adequado.

$\mathrm{Na}$ União Europeia que, em sua regulamentação, traz elemento de conexão específico para serviços digitais, valendo-se do critério de "intervenção humana", para distingui-los dos serviços em seu formato tradicional, os serviços de arquitetura, a depender da forma como são fornecidos, podem sair da regra de conexão do local do imóvel ou móvel. Assim, se os projetos de arquitetura são pré-produzidos e vendidos online, por download, pela disciplina europeia, categorizam-se como serviços digitais..$^{23}$

A despeito da aparente simplicidade e objetividade na aplicação desses elementos de conexão, há diversas formas de sua operacionalização, como por exemplo, no modelo da União Europeia, listam-se quais são os serviços a serem submetidos, ao passo que no direito australiano e neozelandês, traça-se um princípio básico de aplicação, a ser analisado em cada caso concreto (MILLAR, 2009, p. 304).

\subsection{Local do efetivo consumo}

O local do efetivo consumo é elemento de conexão também conhecido como "use or enjoyment rule", ou seja, a "regra do uso ou gozo", em uma tradução literal - busca-se o local onde houve o efetivo consumo do bem.

De acordo com a teoria da tributação indireta, o objeto da tributação seria o consumo, o que muitas vezes não pode ser apreendido, em face da infinitude de possibilidades da realidade fenomênica. Os elementos de conexão são representações jurídicas ou elementos indicativos do consumo, proxies, que viabilizam a tributação.

Em face dessa dificuldade, alguns doutrinadores afirmam que a regra "use or enjoyment" não seria propriamente um elemento de conexão, porém um teste de consumo, que enfoca um específico local, onde determinado adquirente de bens o consome.

A OCDE afirma que se visa, em última instância, a identificar o local do efetivo uso ou consumo dos serviços, respectivamente nas transações B2B e B2C. Entretanto, o legislador pode se valer de presunções, em consonância com características de cada serviço, para possibilitar a tributação. ${ }^{24}$

23 Cf. RENDAHL, Pernilla. Cross-Border consumption taxation of digital supplies. The Netherlands: IBFD, 2009. (Doctoral Series, 18). Capítulo 5, p. 17.

24 Nas palavras empregadas no original:

3.6 In theory, place of taxation rules should aim to identify the actual place of business use for business-tobusiness supplies (on the assumption that this best facilitates implementation of the destination principle) and the actual place of final consumption for business-to-consumer supplies. However, these Guidelines recognise that place of taxation rules are in practice rarely aimed at identifying where business use or final consumption actually takes place. This is a consequence of the fact that VAT must in principle be charged at 
Entretanto, ao se manifestar sobre a irrelevância do beneficiário efetivo dos serviços, bem como do local do pagamento (com exceção das hipóteses de propósitos elisivos ou evasivos), a OCDE acaba por afastar a possibilidade de aplicação da regra do local do efetivo consumo.

Não há uma definição da regra no âmbito do IVA europeu, porém, a partir do "VAT Package" ou o pacote para o IVA de $2008,{ }^{25}$ vê-se a introdução do critério do efetivo consumo, aparentemente como de interpretação das regras de conexão, como se pode depreender do item 3 do seu preâmbulo, quando afirma que "relativamente a todas as prestações de serviço, o lugar de tributação deverá, em princípio, ser o lugar de seu consumo efetivo".

No julgado Athesia Druck, de 19/02/2009, a Corte Europeia decidiu-se pelo emprego da regra do efetivo consumo, para serviços de publicidade (RENDAHL, 2009, p. 9). Nesse caso, uma empresa austríaca (à época, 1993, a Áustria não fazia parte da União Europeia) adquiriu espaço publicitário na mídia italiana, para publicidade de seus clientes alemães e austríacos. Decidiu-se pela regra use or enjoyment, que o local do efetivo consumo dos serviços de publicidade ocorreu na Itália, uma vez que fornecidos à mídia desse país, onde o material foi disseminado.

No âmbito do GST Act australiano há a previsão de dois tipos de regra use or enjoyment: (i). a que faz referência ao local em que o serviço é efetivamente usufruído; (ii). a que faz referência ao fornecimento efetuado para um adquirente em um lugar, porém, recebido por outra pessoa, em outro local, de maneira que a sua localização representa o local do efetivo consumo do serviço. E em face dessas regras, há previsões específicas (MILLAR, 2004, p. 70-72). Verifica-se o local onde foram efetivamente usufruídos os bens, nas hipóteses de leasing de bens corpóreos, fornecimento de direitos de uso, os serviços de agência de viagens e serviços de telecomunicação.

E nesse contexto, o regime australiano adota, expressamente, a regra do beneficiário efetivo (exceto no caso dos serviços prestados em bens corpóreos), se a pessoa que receber o serviço, for distinta daquela prevista como tomadora, no contrato, a Comissão de Tributação entende, nesses termos, que o lugar do efetivo consumo ou "effective use or enjoyment" é o local onde o serviço é provido, denominado esse elemento de conexão de "place of receipt proxy" ou de local de recebimento. A regra do beneficiário

or before the time when the object of the supply is made available for business use or final consumption. In most cases, at that time the supplier will not know or be able to ascertain where such business use or final consumption will actually occur. VAT systems therefore generally use proxies for the place of business use or final consumption to determine the jurisdiction of taxation, based on features of the supply that are known or knowable at the time that the tax treatment of the supply must be determined.

25 Diretiva do Conselho 2008/8/EC de 12/02/2008, que emendou a Diretiva 2006/112/EC. 
efetivo aplica-se especialmente, mas não exclusivamente, aos serviços de publicidade, transporte internacional (objeto de regime jurídico específico) e serviços de treinamento.

\subsection{Local de pagamento}

Sob a perspectiva tributária, os tributos indiretos visam sobre os gastos com o consumo de bens. É dizer, não é o "consumo", enquanto ato de extrair de um bem a sua utilidade, o evento relevante para a tributação, mas o ato de um sujeito aplicar a sua renda para obtenção de algo que satisfaça as suas necessidades e essa última, é perspectiva relevante para efeitos de tributação, pois aí se poderá flagrar a capacidade contributiva (TEIXEIRA, 2002, p. 39). ${ }^{26}$

Alfredo Becker afirma que nos tributos indiretos, o fato jurídico "consumo" é traduzido pela conversão da coisa consumida em valor, o seu custo de aquisição, que estabelecerá a base de cálculo do imposto sobre o consumo. ${ }^{27} \mathrm{O}$ evento "consumo" para efeitos tributários, é medido pelo preço pago na aquisição de bens e sobre esse, a incidência recairá.

Nesse mesmo sentido, autores como Michael Keen e Walter Hellerstein, fazendo coro com Sijbren Cnossen, ao se debruçarem sobre a estrutura do imposto sobre o valor agregado, afirmam que a tributação incide sobre os "dispêndios sobre o consumo" e não sobre o consumo per se. O princípio do destino seria uma regra de administração tributária que visa a se aproximar do local do consumo, de maneira prática, e não numa concepção ideal, de se identificar o local onde o consumo efetivamente ocorreu. ${ }^{28}$

26 Nessa perspectiva, Alessandra Machado Brandão Teixeira afirma que:

"Através dessa formulação, pode-se chegar a uma ideia geral acerca do conceito de consumo, sendo que, para o âmbito tributário, merece atenção a concepção que o entende como aplicação das riquezas na satisfação das necessidades econômicas do homem, visto que o direito tributário procura atingir essa capacidade contributiva do homem manifestada nessa aplicação de riquezas para adquirir produtos considerados essenciais". (TEIXEIRA, 2002, p. 39).

27 Em suas palavras:

"O valor deste fato negativo (o consumo da coisa) é o valor da coisa que foi consumida. Este valor obtém-se convertendo-se a coisa numa cifra. Esta conversão em cifra alcança-se: ou por peso ou por medida ou pelo custo de aquisição da coisa. Não o custo de produção daquela coisa, porque neste caso a verdadeira base de cálculo seria a produção e o tributo pertenceria ao gênero jurídico do imposto de produção. Também não se poderia ser o custo de utilização mediante o qual ela é consumida, pois neste caso a base de cálculo seria a utilização e o tributo teria um novo gênero jurídico: imposto de uso.

$[\ldots]$

Quando a regra jurídica de tributação escolhe para base de cálculo (entre os múltiplos fatos que compõem a sua hipótese de incidência) o fato consistente no consumo de coisa ou serviço, o tributo criado pertencerá ao gênero jurídico do imposto de consumo".

${ }_{28}$ Em suas palavras:

"The fundamental point is that the destination principle is a rule of tax administration that seeks to approximate the location of consumption in a sensible and administrable fashion, not a theoretical ideal that seeks to identify the location where consumption actually occurs. As Rebecca Millar has pointed 
Nessa perspectiva, o local do consumo de um bem terá relevância para efeitos de tributação, se coincidir com o local de onde se originou o dispêndio da renda; ou seja, considerando-se que as condições tecnológicas muitas vezes permitem que sejam dissociadas essas localidades, o direito deverá perseguir o segundo, isto é, o local de pagamento, para o exercício da competência tributária.

Embora a legislação possa eleger diversos elementos de conexão, o fato jurídico do pagamento, bem como a fonte de sua procedência, são enunciados jurídicos suficientes para se presumir o consumo.

Ademais, sobre a tributação direta no comércio eletrônico, afirma Luís Eduardo Schoueri, que o critério de conexão que mais se ajustaria aos desígnios de equidade e justiça na tributação, seria o do princípio da fonte de pagamento, fundado na ideia de sacrifício interestatal, ou seja, a pretensão tributária é do "Estado que vê sua economia depauperada por conta de um pagamento feito ao exterior" (SCHOUERI, 2001, p. 50). ${ }^{29}$ Sob essa perspectiva, a fundamentação teórica da tributação seria o "sacrifício", percebido pela ótica do Estado que tem seus recursos diminuídos pelo pagamento.

Mutatis mutandis, essas ideias podem ser transplantadas aos tributos indiretos, sempre se tendo em vista que o princípio do destino é uma unanimidade no comércio internacional, todavia, na sua aplicação, a utilização de elementos de conexão objetivos, caso da fonte de pagamento, ou subjetivos, como o domicílio do tomador dos serviços, podem levar a efeitos econômicos semelhantes aos concernentes ao princípio da fonte versus residência, na tributação direta.

De acordo com as orientações da OCDE o pagamento não será relevante para fins de determinação da competência tributária. A regra do domicílio do tomador

out (relying on Sijbren Cnossen's description of a VAT as a tax on 'consumption expenditures', rather than a tax on consumption itself), the place of taxation under a VAT should not depend on where actual consumption takes place. Instead, recognizing the transactional nature of a VAT, and the fact that it is a tax on consumption expenditures at the time and place where they are incurred".

29 Em suas palavras:

O que parece passar despercebido que, a par da questão do sacrifício do contribuinte, o qual busca justificar sua tributação individual, torna-se relevante, igualmente, a questão do sacrifício interestatal. Sob este prisma, nasce uma pretensão tributária por parte do Estado que vê sua economia depauperada por conta de um pagamento feito ao exterior. Daí ser possível imaginar, de um lado, um Estado instituindo um imposto sobre ativos no exterior (de que ainda não se cogita, mas que seria viável, do ponto de vista econômico, ainda que indesejável por desincentivar as transações internacionais), e, de outro, um imposto sobre os rendimentos pagos ao exterior (tributação na fonte). Note-se que, aqui, já não se cogita mais em justificar o montante do imposto na capacidade contributiva manifestada, ou nos benefícios oferecidos pelo Estado, mas exclusivamente na circunstância de o Estado ter sua economia nacional diminuída dos recursos enviados ao exterior. O ‘sacrifício’ surge, pois, sob nova forma. Agora, já não mais se trata da circunstância de um rendimento haver sido produzido sob o manto protetor de um Estado (enfoque de benefício), mas de ele ser pago com recursos provenientes do estado (enfoque do pagamento). 
de serviço, contratualmente consignado, sobrepõe-se, mesmo que ele não suporte financeiramente a prestação.

Nas hipóteses de aquisição de serviços no bojo de um grupo econômico multinacional, em que uma empresa é responsável pelos pagamentos dos bens que serão usufruídos pelas demais, esse fato será irrelevante para determinação da jurisdição fiscal competente. ${ }^{30}$

Ambas as proposições combinadas, demonstram que, para a OCDE, não será relevante elementos de conexão objetivos - local da fonte do pagamento e do efetivo consumo - ou seja, o Estado que suportou o consumo, não fará, necessariamente, jus ao tributo, o que, na mesma linha das críticas acerca da tributação direta, acaba por desfavorecer os países importadores de serviços, que, crescentemente, no âmbito de uma economia globalizada, dependem de serviços e intangíveis de forma geral, para agregar tecnologia à sua produção.

Por outro lado, sob o ponto de vista da igualdade entre os Estados, considerando-se que na tributação direta prevalece o princípio da residência, sendo adotada mundialmente a Convenção Modelo da OCDE, haveria justiça fiscal se na tributação indireta, fosse tomado como conexão, o local do pagamento.

Outro aspecto a favorecer o pagamento como elemento de conexão, é o fato de que, no comércio eletrônico, o princípio da fonte de pagamento seria bastante prático, em vista da dificuldade de se buscar a fonte de produção do rendimento, pois os consumidores finais não estão propensos a criar estruturas de pagamento para afastar tributos, como potencialmente estariam os beneficiários dos rendimentos, que podem se socorrer de estruturas de paraísos fiscais e outras formas de planejamentos (SCHOUERI, 2001, p. 51).

30 Nesse sentido, o comentário 3.54 das orientações para o IVA:

3.54 Particular care may be required where payment flows differ from the flows of services or intangibles. Typically, a customer pays a supplier for services or intangibles supplied under a business agreement. However, there may be circumstances where another party may pay for that supply. For instance, it is common for multinational groups of businesses to reduce costs by appointing a company within a group to be the "paymaster" responsible for payments under the relevant agreement to pay for services and intangibles acquired. In such cases, services or intangibles supplied by the supplier or the supplier's foreign subsidiaries to foreign customers may be paid for by the customer's parent business located in the supplier's jurisdiction, although the supplies may not be made to the parent business (See Annex 1 to this Chapter-Example 5). When the general rule is applied, the place of taxation should be decided for each supply individually. The direction of the payment flows and the identity and location of the payer are not, in themselves, relevant. The payment flows are consideration for the supplies under the relevant business agreements but do not, in themselves, create additional supplies, alter the supplies, nor identify the customer or customer location. Accordingly, the supplier makes the supply to the customer identified in the relevant business agreement and the place of taxation is that customer's location. As long as there is no evasion or avoidance, the supplier is therefore entitled to make a supply free of VAT to a foreign customer even if that supply is paid by a third party business located in the same jurisdiction as the supplier. (OECD, 2015a, p. 36). Disponível em: <http://www.oecd.org/ctp/consumption/international-vat-gst-guidelines.pdf>. 
Com efeito, o pagamento, sob a ótica da praticabilidade, é um elemento de conexão eficaz, pois se o serviço, em muitas situações, for de difícil rastreabilidade no mundo fenomênico, quanto ao pagamento, é possível apreendê-lo, pois se manifesta, juridicamente, na celebração de contratos de câmbio, transações com cartões de crédito, procedimentos que podem ser perseguidos pelas administrações tributárias.

Tal dificuldade é contundente nas hipóteses em que tanto o bem é incorpóreo quando o meio para a sua aquisição, como nas transações com softwares por download, projetos de arquitetura, pareceres jurídicos, transmitidos pela internet.

Nas transações com mercadorias, a corporeidade do bem e os controles aduaneiros determinam que o local de entrega seja um elemento de conexão mais eficiente. Na zona primária de um país é possível que se controle a arrecadação, além de se assegurar o crédito tributário, pois a própria mercadoria presta-se como garantia. (WILLIAMS, 2000, p. 192).

Finalmente e não menos importante, no comércio internacional o primordial escopo dos Estados é o ingresso de divisas, sendo quaisquer outros objetivos, acessórios a esse, sendo razoável se considerar que a legislação do comércio exterior convirja nessa direção.

\section{Conclusões}

O presente trabalho teve como objetivo trazer um breve panorama de técnicas de tributação empregadas para a tributação do comércio exterior de serviços e intangíveis.

Segundo dados abertos do Banco Mundial, ${ }^{31}$ em 2016, cerca de 65\% do produto interno bruto da economia mundial advém dos serviços, enquanto no Brasil, esse percentual sobe para 73,3\%. Esses valores compreendem novos signos de riqueza, a serem apreendidos pelos fiscos mundiais.

Contudo, a estruturação da tributação dos serviços e intangíveis trazem dificuldades aos legisladores de todo o mundo, a começar pelo fato de que o direito está edificado para regular comportamentos em um ambiente de tangibilidade. Outra premissa relevante, é que o setor de serviços é categoria residual, construído após a delimitação dos setores primário (que envolve a agricultura e a extração mineral) e secundário (abrangendo a indústria e a manufatura), o que acaba por incluir nesse conjunto, um universo bastante heterogêneo de bens.

Nesse contexto, impõe-se o amplo debate sobre essa nova realidade descortinada à tributação. Assim, o Base Erosion and Profit Shifting - BEPS, plano de

\footnotetext{
31 Disponível em: $<$ https://data.worldbank.org/indicator/NV.SRV.TOTL.ZS $>$.
} 
ação da OCDE em conjunto com os países do G-20, publicado em 2013, ${ }^{32}$ que adota medidas para harmonização da legislação tributária internacional e para o combate à erosão da base tributável, teve como primeira ação identificar os desafios decorrentes da economia digital. E em vista dos grandes desafios trazidos pela economia digital, o tema perpassará todos os planos de ação do BEPS e deve ser objeto de contínuo "pós-BEPS" monitoramento, que deve resultar em um novo relatório, em 2020. ${ }^{33}$

Nesses debates, é fundamental a participação do Brasil, especialmente em um momento em que a discussão da reforma tributária está em pauta.

Brasília, 27 de abril de 2018.

\section{Referências}

ADONNINO, Pietro. El establecimiento permanente como garantía del equilibrio de la fiscalidad internacional considerando los nuevos modelos de actividades de empresa. In: UCKMAR, Victor; ALTAMIRANO, Alejandro C.; TÔRRES, Heleno Taveira. Impuestos sobre el comercio internacional. Buenos Aires: Editorial Ábaco de Rodolfo de Palma, 2003.

BECKER, Alfredo Augusto. Teoria geral do direito tributário. 4. ed. São Paulo: Noeses, 2007. p. 437.

EUROPEAN UNION. Explanatory notes on EU VAT place of supply rules on services connected with immovable property that enter into force in 2017. Oct. 2015. Disponível em: $<$ https://ec.europa. eu/taxation_customs/sites/taxation/files/resources/documents/taxation/vat/how_vat_works/ explanatory_notes_new_en.pdf>.

EUROPEAN UNION. Judgment on the Court (Second Chamber) of 4 July 1985. 1985. Disponível em: <http://eur-lex.europa.eu/legal-content/EN/TXT/?uri=CELEX\%3A61984CJ0168>.

GRECO, Marco Aurélio. Aspectos tributários do comércio eletrônico. In: UCKMAR, Victor; ALTAMIRANO, Alejandro C.; TÔRRES, Heleno Taveira. Impuestos sobre el comercio internacional. Buenos Aires: Editorial Ábaco de Rodolfo de Palma, 2003. p. 879.

. Internet e o direito. 2. ed. São Paulo: Dialética, 2000. p. 56.

GREGGI, Marco. Rethinking the place of consumption: new issues under the VAT system, and the possible consequences on third countries businesses. Legal Studies Research Paper Series,

32 Disponível em: $<$ http://www.oecd.org/ctp/policy-brief-beps-2015.pdf $>$.

33 Addressing The Tax Challenges of the Digital Economy, p. 13. Disponível em: <http://www.oecd.org/ctp/ addressing-the-tax-challenges-of-the-digital-economy-action-1-2015-final-report-9789264241046-en. htm>. 
Australia, Jan. 2010. Monash University Department of Business Law \& Taxation Research Paper n. 1531365. p. 708. Disponível em: <http://ssrn.com/abstract=1531365>.

HELLERSTEIN, Walter. Interjurisdictional issues in the design of a VAT. Tax Law Review, New York, NY, v. 63, n. 2, p. 359-408, 2010. Disponível em: <https://ssrn.com/abstract=1669530>.

. Jurisdiction to impose and enforce income and consumption taxes: towards a unified conception of tax nexus? In: LANG, Michael; MELZ, Peter; KRISTOFFERSSON, Eleonor (Ed.). Value added tax and direct taxation: similarities and differences. The Netherlands: IBFD, 2009. p. 554.

MACEDO, Alberto. ISS e PIS-Cofins-Importação - critérios espacial e pessoal na prestação internacional de serviços. Revista Dialética de Direito Tributário, São Paulo, n. 187, p. 9-28, 2011. p. 22.

MATSUSHITA, Mitsuo et al. The World Trade Organization: law, practice, and policy. New York: Oxford University Press, 2003. p. 235.

MILLAR, Rebecca. Echoes of source and residence in VAT jurisdictional rules. In: LANG, Michael; MELZ, Peter; KRISTOFFERSSON, Eleonor (Ed.). Value added tax and direct taxation: similarities and differences. The Netherlands: IBFD, 2009.

. GST issues for international services transactions. Australian GST Journal, Sydney, v. 4, n. 11, p. 285-308, 2004. p. 285.

Jurisdictional reach of VAT. In: KREVER, Richard (Ed.). VAT In Africa. Pretoria: The Pretoria University Law Press, 2008. p. 175-214. Disponível em: <http://www.pulp.up.ac.za/ component/edocman/vat-in-africa/download?Itemid=>.

; MCCARTHY, Denis. The future of indirect taxation: recent trends in VAT and GST systems around the world. Legal Studies Research Paper Series, Australia, Jun. 2012. Sydney Law School Research Paper 12/40. Disponível em: <https://ssrn.com/abstract=2082674>.

NABAIS, José Casalta. Direito fiscal. 3. ed. Coimbra: Almedina, 2005.

OECD. International VAT/GST guideline. Paris: [s.n.], Nov. 2015a. Disponível em: < http://www. oecd.org/ctp/consumption/international-vat-gst-guidelines.pdf $>$.

OECD. Taxation and electronic commerce: implementing the Ottawa taxation framework conditions. Paris: [s.n.], 2001. Disponível em: <http://www.oecd.org/tax/consumption/Taxation $\% 20$ and\%20 eCommerce\%202001.pdf $>$.

OECD. Taxing multinational enterprises: Base Erosion and Profit Shifting (BEPS). Paris: [s.n.], Oct. 2015b. Disponível em: <http://www.oecd.org/ctp/policy-brief-beps-2015.pdf>.

RENDAHL, Pernilla. Cross-Border consumption taxation of digital supplies. The Netherlands: IBFD, 2009. (Doctoral Series, 18). 
SCHOUERI, Luís Eduardo. Imposto de renda e o comércio eletrônico. In: SCHOUERI, Luís Eduardo. Internet: o direito na era virtual (Org.). 2. ed. Rio de Janeiro: Forense, 2001. p. 39-55. p. 50 .

. ISS sobre a importação de serviços do exterior. Revista Dialética de Direito Tributário, São Paulo, n. 100, p. 39-51, jan. 2004. p. 48.

SEVILLA SEGURA, José V. Politica y técnica tributarias. Madrid: Instituto de Estudios Fiscales, 2004. p. 473.

TEIXEIRA, Alessandra Machado Brandão. A tributação sobre o consumo de bens e serviços. Belo Horizonte: Livraria Mandamentos Editora, 2002.

TERSI, Vinicius Feliciano. A eficácia do conceito de 'beneficiário efetivo' como instrumento de prevenção da evasão fiscal nas convenções internacionais para evitar a bitributação. Direito Tributário Atual, São Paulo, n. 32, p. 382-414, 2014.

TROIANELLI, Gabriel Lacerda; GUEIROS, Juliana. O ISS e exportação e importação de serviços. In: PEIXOTO, Marcelo Magalhães; MARTINS, Ives Gandra da Silva. (Coord.). ISS LC 116/2003: à luz da doutrina e da jurisprudência. Curitiba: Juruá, 2004. p. 199-208.

UNIÃO EUROPEIA. Regulamento de Execução (UE) n. 282/2011 do Conselho de 15 de março de 2011 que estabelece medidas de aplicação da Directiva 2006/112/CE relativa ao sistema comum do imposto sobre o valor acrescentado. Mar. 2011. Disponível em: $<$ http://eur-lex.europa.eu/legalcontent/PT/TXT/PDF/?uri=CELEX:32011R0282\&qid=1458995613456\&from=EN $>$.

WILLIAMS, David. Value-added tax. In: THURONYI, Victor. (Ed). Tax law design and drafting. The Hague: Kluwer Law International, 2000. v. 1.

XAVIER, Alberto. Direito tributário internacional. 2. ed. atualizada. Coimbra: Edições Almedina, 2009. 